\title{
Nurses’ Use of Complementary Alternative Medicine for Cancer Patients in Japan
}

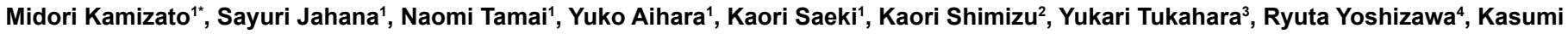
Hamada $^{1}$, Kayo Nagano ${ }^{1}$, Mieko Taira ${ }^{1}$, Risa Takamiya ${ }^{1}, K_{\text {Kumiko Tamashiro }}{ }^{\text {and Mizuho Tajima }}{ }^{5}$

${ }^{1}$ Graduate School of Nursing, Okinawa Prefectural College of Nursing, Japan

${ }^{2}$ Department of Nursing, Faculty of Human Health, Meio University, Japan

${ }^{3}$ Yukary's aroma therapy, Japan

${ }^{4}$ Naha- City Hospital, Japan

${ }^{5}$ National Cancer Center Hospital East, Japan

\section{Abstract}

Purpose/Objective: To identify oncology nurses' use of complementary and alternative medicine (CAM) for cancer patients in Japan.

Design: Descriptive, cross sectional.

Setting: Five central cancer hospitals, five general hospitals, and four Palliative Care Units in Japan.

Sample: A convenience sample consisting of 1134 oncology nurses with a Japanese Nursing license.

Methods: A researcher-developed self-reported questionnaire for CAM was delivered to nurses who were involved with cancer patients in hospitals and palliative care units (PCU).

Findings: The response rate was $71 \%(801 / 1134)$. The nurses' knowledge of CAM was $42 \%$ (40\% in hospitals and $68.4 \%$ in PCU). The use of CAM for nursing practice was $29.4 \%$ (26\% in hospitals and $71 \%$ in PCU). The types of CAM used were massage therapy $(78 \%)$, lymph drainage $(46 \%)$, aromatherapy $(43 \%)$, touching $(42 \%)$, music therapy $(33 \%)$, acupressure and breathing $(19 \%)$, hot pack therapy $(16 \%)$, acupuncture $(13 \%)$. Barriers of using CAM in nursing practice were because of insufficient skill $(73 \%)$ and knowledge $(68 \%)$, and having no time $(70 \%)$ for CAM. However, $80 \%$ of the nurses wanted to use CAM such as aromatherapy $(72 \%)$, massage therapy $(61 \%)$, lymph drainage (53\%), and music therapy (43\%). The purposes of aroma and music therapy use for patients were relaxation, relieving anxiety, pain, insomnia, edema, and fatigue. Fifty-six percent of nurses had been asked by patients about healthy food or supplement. Only $8.7 \%$ of nurses knew about the Cancer CAM guideline (hospitals $8 \%$ vs. PCU $23 \%$ ).

Conclusion: Nurses performing CAM do not yet have sufficient knowledge or utilization practices, and there are difficulties with both skills and time management. However, there is reason to be optimistic about providing safe and effective CAM treatment to cancer patients. Therefore, it is necessary to enhance the education afforded to nurses in order to realize effective CAM usage. Developing CAM educational programs for nurses will be the next step in research with simple and easy to use CAM therapies in nursing practices in Japan.

Keywords: Oncology nurse; Complementary alternative medicine; Knowledge and use

\section{Introduction}

In Japan, $44.6 \%$ (1382 of 3100 ) of cancer patients were using Complementary and Alternative Medicine (CAM) according to a nationwide, cross-sectional survey [1]. This rate was very similar to the update systematic review from 18 countries. This combined prevalence for current use of CAM in cancer was $40 \%$ [2]. Cancer patients' CAM use is common and increasing in a worldwide survey $[3,4]$. CAM was defined by the National Center for Complementary and Alternative Medicine (NCCAM) as "a group of diverse medical and healthcare systems, practices, and products that are not presently considered to be part of conventional medicine" [5]. The majority of Japanese cancer patients prefer natural health products and supplements [1]. However, doctors and nurses in Japan do not recommend these products for cancer patients because there is not enough evidence to support the recommendation. Instead, Japanese nurses in hospice and palliative care units have been providing CAM therapies such as massage therapy, touch, and music therapy for cancer patients [6]. However, there is very limited data about oncology nurses' use of CAM therapies for cancer patients, especially for oncology nurses in general hospitals and cancer centers.

Japan has only 244 (4836 beds) hospices and palliative care units in 2012 [7]. Therefore, the majority of the patients are being treated for cancer or end-of-life care in general hospitals or cancer centers. Also, hospital deaths are higher than home deaths in Japan, the majority of cancer patients die in hospitals (general hospital death: $81 \%$ vs. hospice death: 7\%) [8]. It is important that both nurses in palliative care units and in general hospitals including cancer centers know about CAM therapies to alleviate cancer patients' symptoms of distress during or after cancer treatments and end of life care. The palliative care guidelines recommended non-pharmacological approaches such as CAM therapies for relieving symptoms with pharmacological treatment [9]. However, little is known about oncology nurses' use of CAM therapies for relieving symptoms and educational needs in nursing practice.

The purpose of this study was to identify oncology nurses' use of CAM therapies for cancer patients in Japan.

*Corresponding author: Midori Kamizato, RN, PHN, PhD, Graduate Schoo of Nursing, Okinawa Prefectural College of Nursing, Okinawa, Japan, Tel: +81-98-833-8881; Fax: +81-98-833-8881 or +81-98-833-5133; E-mail: kamizato@okinawa-nurs.ac.jp

Received December 08, 2013; Accepted June 25, 2013; Published July 01, 2013

Citation: Kamizato M, Jahana S, Tamai N, Aihara Y, Saeki K, et al. (2013) Nurses' Use of Complementary Alternative Medicine for Cancer Patients in Japan. J Nurs Care S5: 011. doi: 10.4172/2167-1168.S5-011

Copyright: (c 2013 Hirakawa Y, et al. This is an open-access article distributed under the terms of the Creative Commons Attribution License, which permits unrestricted use, distribution, and reproduction in any medium, provided the original author and source are credited. 


\section{Methods}

This study design was a descriptive, cross-sectional survey using a self-administered questionnaire. Participants were oncology nurses who were employed at 5 central cancer hospitals (range of beds: 236604), 5 general hospitals (range of beds: 40-350), and 4 palliative care units (range of beds: 12 -19) in two regions of Japan. One region was the Kanto district area that was in main land of Japan and, other area was the Southern Island of Okinawa. Ethical approval was obtained from the university and each hospital.

The researchers contacted the nursing director at each medical facility directly by phone, explaining the study's research intentions and securing consent for questionnaire survey implementation. Questionnaire forms were then sent to nursing directors, who then distributed them to nurses working in general cancer wards or cancer patient-specific care wards. There were no specifications of thoroughness or completeness in the surveys, and participants were allowed to respond freely. To address privacy concerns, surveys were written anonymously and a postal envelope accompanied each survey. Upon completion, participants placed their survey in the envelope and dropped them in a locked box. One collection box was placed at each medical facility for an average of two weeks to allow participants to respond. Recovery of surveys was either completed by a nursing director who sent them to a researcher (postage costs borne by the researcher) or a direct pick-up by the researcher. All surveys were performed under written consent, between October and November, 2011.

As the application of CAM is susceptible to cultural influences; both preceding CAM literature and the opinions of specialists in the field provided references to create the contents of the survey. The aspects of the CAM adopted in this study, based on interviews with nurses involved in treating cancer patients and previous research results, are commonly used throughout clinical settings in Japan, or highly likely to be used. After creating the survey, it was given to 12 nurses (not from the sample) who have had experience treating cancer patients. The survey content was altered based on their opinions, thereby helping ensure reliability and validity. The survey was printed on four sheets of paper, with reference materials at the end.

\section{Demographic information}

Nurse's demographics such as age, sex, marriage, nursing experience, and oncology nursing experience were obtained by anonymous questionnaires.

\section{CAM information}

CAM self-reported knowledge, CAM information source, experience of using CAM in nursing practice and types of CAM used, barriers to using CAM, preferred to use CAM types, needs for study of CAM, effect of aroma massage and music therapy, experience of consultation from patients about supplement, knowledge of CAM's prohibited use during cancer treatment, and knowledge of CAM guidelines. We selected 17 CAM therapies such as aromatherapy, massage, music, touch, and art which might be because of ease of use in a busy clinical setting, ease of learning, and popularity among cancer patients and families for inclusion in the educational intervention at the next step on a research study.

Descriptive statistics (means, standard deviations, percentages) were used to analyze oncology nurses' responses to each question. Data analysis performed on the entirety of the data set, as well as on different subsets, such as general hospitals or palliative care units were analyzed. Differences between the two sets of data were assessed using Chi

Square $\left(X^{2}\right)$ for categorical data, and $t$-test $(t)$ for continuous data. The significance level was set at $\mathrm{p}<0.05$ (two-tailed) and all data analyses were conducted using SPSS 11.5 Japanese version for Windows.

\section{Results}

\section{Participant characteristics}

The response rate was $71 \%$ with 801 questionnaires returned. In this study, 787 (69\%) out of 1134 oncology nurses' data were eligible. The participants' characteristics are shown in table 1 . The mean age of the nurses was $36.6 \pm 9.7$ years; $91.6 \%$ were female; nursing experience was $12.5 \pm 9.5$ years; $84.9 \%$ were staff nurses; and $75.3 \%$ were graduates. There were no significant differences between nurses in general care ward and nurses in palliative care unit regarding marital status and educational background. However, there were significant differences between nurses in general ward between nurses in palliative care unite regarding age (35.6 $\pm 9.8: \mathrm{n}=706$ nurses in general hospitals vs. $39.9 \pm 8.5: \mathrm{n}=57$ nurses in palliative care units, $\mathrm{p}<.001)$ and nursing experience $(12.3 \pm 9.6: \mathrm{n}=716$ nurses in general hospitals vs. $15.2 \pm 8.6$ : $\mathrm{n}=56$ nurses in palliative care units, $\mathrm{p}<.02$ ).

\section{CAM self-reported knowledge, CAM information source}

Nurses' CAM knowledge was $42 \%$ ( $n=329)$, of which, 39.9\% ( $n=290)$ nurses in general hospitals and $68.4 \%(\mathrm{n}=39)$ nurses in palliative care units had CAM knowledge. Nurses obtained information on CAM mainly through media, professional journals, books, or magazines (Table 2).

\section{CAM experience and types of CAM used in nursing practice}

CAM therapies were used by $29.4 \%(n=222)$ of nurses $(26.0 \%$ :

Table 1: Demographic Characteristics.

\begin{tabular}{|c|c|c|c|}
\hline & & & $n=774-780$ \\
\hline Demographic Characteristics & Mean \pm SD & $n$ & $\%$ \\
\hline \multicolumn{4}{|l|}{ Gender } \\
\hline \multicolumn{2}{|l|}{ Male } & 64 & 8.1 \\
\hline \multicolumn{2}{|l|}{ Female } & 716 & 91.6 \\
\hline Age, year & \multicolumn{3}{|l|}{$36.6 \pm 9.7$} \\
\hline Nursing experience, year & \multicolumn{3}{|l|}{$12.5 \pm 9.5$} \\
\hline \multicolumn{4}{|l|}{ Marriage Status } \\
\hline \multicolumn{2}{|l|}{ Married } & 368 & 47.5 \\
\hline \multicolumn{2}{|l|}{ Not married } & 406 & 52.5 \\
\hline \multicolumn{4}{|l|}{ Primary work settings } \\
\hline \multicolumn{2}{|l|}{ Inpatient medical department } & 287 & 36.5 \\
\hline \multicolumn{2}{|l|}{ Inpatient surgical department } & 248 & 31.5 \\
\hline \multicolumn{2}{|l|}{ Palliative Care Units } & 57 & 7.2 \\
\hline \multicolumn{2}{|l|}{ Outpatient Center } & 51 & 6.5 \\
\hline \multicolumn{2}{|l|}{ Other } & 144 & 18.3 \\
\hline \multicolumn{4}{|l|}{ Primary position } \\
\hline \multicolumn{2}{|l|}{ Staff nurse } & 660 & 84.9 \\
\hline \multicolumn{2}{|l|}{ Head nurse } & 61 & 7.9 \\
\hline \multicolumn{2}{|l|}{ Nurse manager } & 48 & 6.2 \\
\hline \multicolumn{2}{|l|}{ Certified Nurse } & 7 & 0.9 \\
\hline \multicolumn{2}{|l|}{ Certified Nurse Specialist } & 1 & 0.1 \\
\hline \multicolumn{4}{|l|}{ Education } \\
\hline \multicolumn{2}{|l|}{ Diploma } & 585 & 75.3 \\
\hline \multicolumn{2}{|l|}{ Bachelor } & 127 & 16.3 \\
\hline \multicolumn{2}{|l|}{ Associate } & 45 & 5.8 \\
\hline \multicolumn{2}{|l|}{ Master } & 14 & 1.8 \\
\hline \multicolumn{2}{|l|}{ Other } & 6 & 0.8 \\
\hline
\end{tabular}


Citation: Kamizato M, Jahana S, Tamai N, Aihara Y, Saeki K, et al. (2013) Nurses' Use of Complementary Alternative Medicine for Cancer Patients in Japan. J Nurs Care S5: 011. doi: 10.4172/2167-1168.S5-011

Page 3 of 5

Table 2: CAM information source.

Resources for CAM multiple choice $(n=329)$

\begin{tabular}{|l|c|c|}
\hline & $\mathrm{n}$ & $\%$ \\
\hline Media & 184 & 55.9 \\
\hline Professional Journals & 138 & 41.9 \\
\hline Books or Magazines & 81 & 24.6 \\
\hline Conference & 81 & 24.6 \\
\hline Internet & 71 & 21.6 \\
\hline Family or Friends & 62 & 18.8 \\
\hline Other & 49 & 14.9 \\
\hline
\end{tabular}

Table 3: Types of CAM used in nursing practice.

\begin{tabular}{|l|c|c|}
\hline Types of CAM used & multiple choice $(\mathrm{n}=222)$ & $\%$ \\
\hline Massage & $\mathrm{n}$ & 78.4 \\
\hline Lymph drainage & 174 & 45.9 \\
\hline Aromatherapy & 97 & 43.7 \\
\hline Touch & 94 & 42.3 \\
\hline Music Therapy & 75 & 33.8 \\
\hline Breathing & 42 & 18.9 \\
\hline Shiatsu & 41 & 18.5 \\
\hline Heat Therapy & 35 & 15.8 \\
\hline Acupuncture & 28 & 12.6 \\
\hline Health products·Dietary & 21 & 9.5 \\
\hline supplement & 17 & 7.7 \\
\hline Animal Assisted Therapy & 13 & 5.9 \\
\hline Reflexology & 10 & 4.5 \\
\hline Imaginary Therapy & 7 & 3.2 \\
\hline Art Therapy & 6 & 2.7 \\
\hline Homeopathy & 5 & 2.3 \\
\hline Yoga & 4 & 1.8 \\
\hline Journal Therapy & 4 & 1.8 \\
\hline Other & & \\
\hline & & \\
\hline
\end{tabular}

$\mathrm{n}=182$ nurses in general hospitals vs. $71.4 \%$ : $\mathrm{n}=40$ nurses in palliative care units, $\mathrm{p}<.000)$. The most used CAM therapies were massage therapy, lymph drainage, aromatherapy, touching, and music therapy (Table 3).

\section{Barriers to CAM uses}

Five hundred thirty-five nurses (73.0\%) felt difficulty using CAM therapies (72.8\%: $n=493$ nurses in general hospitals vs. $73.7 \%: n=42$ nurses in palliative care units). The most common barriers were lack of skills, no time for CAM therapies, and lack of knowledge (Table 4).

\section{Preferred types of CAM used and interest in attending educational courses of CAM}

In nursing practice, $80.3 \%(\mathrm{n}=561)$ nurses were interested in using CAM therapies (79.1\%: $n=511$ nurses in general hospitals vs. $94.3 \%$ : $\mathrm{n}=50$ nurses in palliative care units, $\mathrm{p}<.003$ ). The most preferred uses of CAM therapies were aromatherapy, massage therapy, lymph drainage, music therapy, and breathing (Table 5). Four hundred thirty-six nurses (59.3\%) were interested in attending educational courses of CAM (58.7\%: $\mathrm{n}=400$ nurses in general hospitals vs. $66.7 \%$ : $\mathrm{n}=36$ nurses in palliative care units).

\section{Purposes of CAM use for aromatherapy or music therapy}

The main purpose for using aromatherapy was for relaxation, alleviation for pain, reduction of anxiety, improvement in insomnia, reduction of edema, reduction of fatigue, reduction of depression, and improvement of constipation (Table 6). Nurses also used music therapy for relaxation, reduction of anxiety, reduction of depression, alleviation for pain, improvement in insomnia, and reduction of fatigue (Table 6).

Table 4: Barriers to CAM uses.

Barriers to CAM uses multiple choice $(n=535)$

\begin{tabular}{|l|c|c|}
\hline Barriers to CAM uses & multiple choice $(\mathrm{n}=535)$ & $\%$ \\
\hline Lack of skills & $\mathrm{n}$ & 73.5 \\
\hline No time & 393 & 70.3 \\
\hline Lack of knowledge & 376 & 68.0 \\
\hline Can't continue & 364 & 52.7 \\
\hline Hard to decide when to use & 282 & 42.6 \\
\hline Can't evaluate & 228 & 39.3 \\
\hline Financial problem & 210 & 19.1 \\
\hline Hard to get cooperation with staff & 102 & 17.8 \\
\hline No time for explaining to patients & 95 & 17.0 \\
\hline Unnecessary & 91 & 0.9 \\
\hline Other & 5 & 4.9 \\
\hline
\end{tabular}

Table 5: Preferred types of CAM used and interest in attending educational courses of CAM.

\begin{tabular}{|l|c|c|}
\hline Preferred types of CAM used & multiple choice $(\mathrm{n}=561)$ & $\%$ \\
\hline Aromatherapy & $\mathrm{n}$ & 71.8 \\
\hline Massage & 403 & 61.3 \\
\hline Lymph drainage & 344 & 52.4 \\
\hline Music Therapy & 294 & 43.0 \\
\hline Breathing & 241 & 23.9 \\
\hline Reflexology & 134 & 22.3 \\
\hline Shiatsu & 125 & 20.7 \\
\hline Touch & 116 & 19.8 \\
\hline Animal Assisted Therapy & 111 & 16.4 \\
\hline Heat therapy & 92 & 13.4 \\
\hline Imaginary Therapy & 75 & 7.8 \\
\hline Art Therapy & 44 & 7.8 \\
\hline Yoga & 44 & 7.1 \\
\hline Acupuncture & 40 & 6.1 \\
\hline Journal Therapy & 34 & 5.3 \\
\hline Health & 30 & 3.9 \\
\hline supplement & 22 & 3.9 \\
\hline Homeopathy & 22 & 1.6 \\
\hline Other & 9 & \\
\hline & & \\
\hline
\end{tabular}

Table 6: Purpose of using Aroma and Music therapy.

Purpose of using Aroma and Music therapy multiple choice

\begin{tabular}{|l|c|c|c|c|}
\hline \multirow{2}{*}{} & \multicolumn{2}{|c|}{ Aroma $\mathrm{n}=123$} & \multicolumn{2}{c|}{ Music $\mathrm{n}=141$} \\
\cline { 2 - 5 } & $\mathrm{n}$ & $\%$ & $\mathrm{n}$ & $\%$ \\
\hline Relaxation & 123 & 100.0 & 140 & 99.3 \\
\hline Alleviation of pain & 84 & 68.3 & 48 & 34.0 \\
\hline Reduction of anxiety & 82 & 66.7 & 74 & 52.5 \\
\hline $\begin{array}{l}\text { Improvement } \\
\text { insomnia }\end{array}$ & 66 & 53.7 & 44 & 31.2 \\
\hline in & 52 & 42.3 & - & - \\
\hline Reduction of edema & 49 & 39.8 & 25 & 17.7 \\
\hline $\begin{array}{l}\text { Reduction of fatigue } \\
\text { depression }\end{array}$ & 34 & 27.6 & 52 & 36.9 \\
\hline $\begin{array}{l}\text { Improvement } \\
\text { constipation }\end{array}$ & 21 & 17.1 & - & - \\
\hline Other & 1 & 0.8 & 13 & 9.2 \\
\hline
\end{tabular}


Table 7: Types of dietary supplements being consulted.

\begin{tabular}{|l|c|c|}
\hline \multicolumn{3}{|c|}{ Types of dietary supplements being consulted multiple choice $(\mathrm{n}=432)$} \\
\hline Agaricus & $\mathrm{n}$ & $\%$ \\
\hline Propolis & 293 & 67.8 \\
\hline Vitamins & 160 & 37.0 \\
\hline Royal jelly & 142 & 32.9 \\
\hline Fucoidan & 129 & 29.9 \\
\hline Chlorella & 99 & 22.9 \\
\hline Shark Cartilage & 94 & 21.8 \\
\hline Turmeric & 88 & 20.4 \\
\hline EM(Effective Microorganisms) & 85 & 19.7 \\
\hline Protein & 59 & 13.7 \\
\hline Prune & 46 & 10.6 \\
\hline Phellinus linteus & 44 & 10.2 \\
\hline Gauoderma lucidum & 41 & 9.5 \\
\hline Chitin & 34 & 7.9 \\
\hline AHCC & 32 & 7.4 \\
\hline Other & 9 & 2.1 \\
\hline & 48 & 11.1 \\
\hline
\end{tabular}

Table 8: Types of responses that patients asked about dietary supplements.

\begin{tabular}{|l|c|c|}
\hline $\begin{array}{l}\text { Types of responses that patients asked } \\
\text { about dietary supplements multiple choice }(\mathrm{n}=432)\end{array}$ \\
\hline & $\mathrm{n}$ & $\%$ \\
\hline Consulted with primary doctor & 382 & 88.4 \\
\hline Giving advice with limited knowledge & 144 & 33.3 \\
\hline No advice & 23 & 5.3 \\
\hline Giving advise after referred book & 13 & 3.0 \\
\hline Other & 21 & 4.9 \\
\hline
\end{tabular}

Experience of having a consultation from patients regarding dietary supplement and knowledge of the guidelines

Nurses' experiences of consultation from patients regarding dietary supplement was $56.4 \%: \mathrm{n}=432(54.4 \%: \mathrm{n}=386$ nurses in general hospitals vs. $82.1 \%: \mathrm{n}=46$ nurses in palliative care units, $\mathrm{p}<.000$ ). Most of the consultations were about agarics, propolis, vitamin, royal jelly, and fucoidan (Table 7). When nurses consulted with patients, they were referred to a doctor for consultation (Table 8). Nurses' knowledge of Japanese CAM guidelines was 8.7\%: $\mathrm{n}=66$ (7.5\%: $\mathrm{n}=53$ nurses in general hospitals vs. $23.2 \%: \mathrm{n}=13$ nurses in palliative care units, $\mathrm{p}<.000)$ and nurses' knowledge of supplements 'prohibition during cancer treatment was $29 \%$ : $n=223$ (28.8\%: $n=205$ nurses in general hospitals vs. $32.7 \%$ : $\mathrm{n}=18$ nurses in palliative care units).

\section{Discussion}

In this study, overall $29.4 \%$ of oncology nurses had experienced using CAM for cancer patients. Oncology nurses' CAM uses for patients in general hospitals $(26 \%)$ were low rate compared to palliative care units (68.4\%). Several CAM surveys in palliative care settings in Japan or other countries reported that about $60-90 \%$ of nurses provided CAM in practice [6,10-12]. Those previous studies and our results indicate that oncology nurses in palliative care unites might have enough time or skills and knowledge for patients providing CAM therapy compare to oncology nurses in general hospitals. However, most cancer patients in Japan were in general hospitals without palliative care unit, including cancer hospitals or centers [8]. Therefore, Japan needs to consider providing CAM not only for patients in palliative care units but also for patients in general wards or hospitals. In our study, general hospitals included acute or terminal cancer patients. If nurses provide CAM therapy in this busy clinical settings, CAM therapy needs to be easy and simple to use. Hessig et al. [13] found that lack of time was the main deterrent impeding use of complementary therapies in their practice. They developed a one-day CAM educational program for nurses with selecting CAM for quite easily throughout the day in to the nursing care. Results of their research, a one day CAM educational intervention was successful in enhancing nurses' knowledge. Developing CAM educational programs for nurses will be the next step in research with simple and easy-to-use CAM therapies in nursing practices in Japan. We also need to develop CAM delivery systems that require less effort on the part of the busy staff nurse such as general ward. CAM guidelines show evidence of alleviation of distress symptoms such as pain, fatigue, anxiety and depression with cancer patients [14-16]. Also, NCCN guidelines recommend pharmacologic treatments with nonpharmacologic approaches such as CAM therapies [9]. Nurses need to have this knowledge and skill to alleviate distress symptoms among cancer patients. Though this study embodies a relatively small number of nurses from Japan, the results indicate that aromatherapy and music therapy did indeed provide symptom relief to cancer patients. Therefore, we propose that nurses should learn CAM skills in order to contribute to the improvement of the quality of life of cancer patients.

The most common therapies implemented in nursing practice were massage therapy, following lymph drainage, aromatherapy, touch, and music therapy. These findings, except for lymph drainage, were similar to the findings of other studies in the United States, Canada, Australia, and Taiwan [11,17-19] . Nitta et al. [6] reported that $95 \%$ of nurses provided massage therapy as a daily nursing care in palliative care settings [20]. These nurses also derived lymph drainage with special certificates. Providing safe CAM therapies is a very important nursing practice. This survey mentioned that lack of skills and time were barriers for using CAM. These barriers were common in several papers $[12,18,20,21]$. Even though barriers existed, most nurses in our study and previous studies $[6,22,23]$ were interested in learning and using CAM. In another aspect of the research, some nurses just wanted to learn more about CAM for communicating confidently with patients for providing accurate information [24]. There are many things that cancer patients do not tell doctors or nurses, therefore it is often difficult to discern whether or not CAM is being performed in an appropriate manner. An assessment on the safety of CAM treatments is certainly necessary, and this requires forming a relationship of mutual trust between doctors, and patients and their families. According to a national survey in Japan, more than half of the cancer patients were taking some supplemental product and spending, on average, US $\$ 500$ a month [1]. Cancer patients were seeking information about supplements from nurses, however, most nurses had difficulty responding to cancer patients' questions about supplements because of lack of knowledge. Nurses need to have knowledge on supplements including the interaction of antioxidants during cancer treatments. However, nurses' knowledge of supplements' prohibition during cancer treatment was low rate $(29 \%)$ in our research. Antioxidants may theoretically reduce the effectiveness of chemotherapy and radio-therapy by lowering oxidative damage [25].

According to previous study [25] show that healthcare providers in many countries do not have sufficient knowledge about this issue. Oncology nurses should increase their knowledge about CAM therapies to decrease possible negative and detrimental effects of CAM use. In Yasemin's research, $10 \%$ of patients reported nausea, vomiting, or allergic reactions as adverse effects, however the researcher mentioned that this might be an underestimation [25]. Majority patients did not inform many unwanted effects of CAM therapies [26]. Oncology nurses should be aware that most supplements' adverse effects during cancer 
treatments. Although Japanese CAM guidelines [27] were available in the Internet, only about $9 \%$ of nurses knew CAM guidelines. These CAM guidelines [27] showed strong evidence of massage and aromatherapy, which most nurses desire to use, and showed low levels of evidence for supplemental products. Nurses need to know that information so they can have discussions with patients. Nurses are responsible for patients to provide knowledge and education about CAM.

The main strength of this survey is that it used a large sample size with urban and rural geographic areas. The samples were obtained from the largest cancer center in the Kanto district area, and the Southern Island of Okinawa, all the main general hospitals, and all palliative care units. Several limitations existed for this survey. Our questionnaire did not cover all aspects of CAM use and knowledge. Frequency and time of CAM use needed to be included in the questionnaire. Each nurse's educational CAM background or institutions of financial support and policies for CAM might be an influenced for using CAM or might be barriers in nursing practice. Further, the data did not analyze CAM's relation to demographic data.

In conclusion, nurses performing CAM do not yet have sufficient knowledge or utilization practices, and there are difficulties with both skills and time management. However, there is reason to be optimistic about providing safe and effective CAM treatment to cancer patients. Therefore, it is necessary to enhance the education afforded to nurses in order to realize effective CAM usage. Developing CAM educational programs for nurses will be the next step in research with simple and easy to use CAM therapies in nursing practices in Japan.

\section{Acknowledgment}

This study was supported by a Grant-in-Aid for Scientific Research (C) from the Ministry of Education, Culture, Sports, Science, and Technology of Japan.

\section{References}

1. Hyodo I, Amano N, Eguchi K, Narabayashi M, Imanishi J, et al. (2005) Nationwide survey on complementary and alternative medicine in cancer patients in Japan. J Clin Oncol 23: 2645-2654.

2. Horneber M, Bueschel G, Dennert G, Less D, Ritter E, et al. (2012) How many cancer patients use complementary and alternative medicine: a systematic review and metaanalysis. Integr Cancer Ther 11: 187-203.

3. Ernst E, Cassileth BR (1998) The prevalence of complementary/alternative medicine in cancer: a systematic review. Cancer 83: 777-782.

4. Ernst E (2000) Prevalence of use of complementary/alternative medicine: a systematic review. Bull World Health Organ 78: 252-257.

5. NCCAM. What is complementary and alternative medicine (CAM)? (2009) National Center for Complementary and Alternative Medicine website.

6. Nitta N, Kawabata K (2007) Level of awareness and practice of complementary and alternative medicine in nursing-survey of nurses in palliative care unit with regard to training and alternative medicine (original is Japanese). Japanese Society for Complementary and Alternative Medicine 4: 23-31.

7. Hospice Palliative Care Japan (2012) http://www.hpcj.org/uses/pcumap.html (original is Japanese). [Accessed November 5, 2012].

8. Palliative Care (2012) Palliative Care in Japan (original is Japanese), Tokyo MC medic press

9. National Comprehensive Cancer Network (2013) NCCN Guidelines for supportive care.
10. Molassiotis A, Fernadez-Ortega P, Pud D, Ozden G, Scott JA, et al. (2005) Use of complementary and alternative medicine in cancer patients: a European survey. Ann Oncol 16: 655-663.

11. Demmer C (2004) A survey of complementary therapy services provided by hospices. J Palliat Med 7: 510-516.

12. Oneschuk D, Balneaves L, Verhoef M, Boon H, Demmer C, et al. (2007) The status of complementary therapy services in Canadian palliative care settings. Support Care Cancer 15: 939-947.

13. Hessig RE, Arcand LL, Frost MH (2004) The effects of an educational intervention on oncology nurses' attitude, perceived knowledge, and selfreported application of complementary therapies. Oncol Nurs Forum 31: 71-78.

14. Abrams D, Weil A (2008) Integrative oncology, Oxford University Press Inc., Oxford.

15. Decker GM, Lee CO (2010) Handbook of Integrative Oncology Nursing: Evidence-Based Practice. Oncology Nursing Society, Pittsburgh, PA.

16. Deng GE, Frenkel M, Cohen L, Cassileth BR, Abrams DI, et al. (2009) Evidencebased clinical practice guidelines for integrative oncology: complementary therapies and botanicals. J Soc Integr Oncol 7: 85-120.

17. Shorofi SA, Arbon P (2010) Nurses' knowledge, attitudes, and professional use of complementary and alternative medicine (CAM): a survey at five metropolitan hospitals in Adelaide. Complement Ther Clin Pract 16: 229-234.

18. Chu FY, Wallis M (2007) Taiwanese nurses' attitudes towards and use of complementary and alternative medicine in nursing practice: a cross-sectional survey. Int J Nurs Stud 44: 1371-1378.

19. Arahata T, Komatsu $H$ (2010) A study on the use of massage by nurses to relieve cancer pain and factors affecting this usage (original is Japanese). 5 101-13.

20. Rojas-Cooley MT, Grant M (2009) Complementary and alternative medicine: oncology nurses' knowledge and attitudes. Oncol Nurs Forum 36: 217-224.

21. Tracy MF, Lindquist R, Savik K, Watanuki S, Sendelbach S, et al. (2005) Use of complementary and alternative therapies: a national survey of critical care nurses. Am J Crit Care 14: 404-414.

22. Rojas-Cooley MT, Grant M (2006) Complementary and alternative medicine: oncology nurses' experiences, educational interests, and resources. Oncol Nurs Forum 33: 581-588

23. Hayes KM, Alexander IM (2000) Alternative therapies and nurse practitioners: knowledge, professional experience, and personal use. Holist Nurs Pract 14: 49-58.

24. Halcón LL, Chlan LL, Kreitzer MJ, Leonard BJ (2003) Complementary therapies and healing practices: faculty/student beliefs and attitudes and the implications for nursing education. J Prof Nurs 19: 387-397.

25. Yildirim $Y$ (2010) Patterns of the use of complementary and alternative medicine in women with metastatic cancer. Cancer Nurs 33: 194-200.

26. Molassiotis A, Scott JA, Kearney N, Pud D, Magri M, et al. (2006) Complementary and alternative medicine use in breast cancer patients in Europe. Support Care Cancer 14: 260-267.

27. Japanese Society for Palliative Medicine (2008). Complimentary alternative medicine for cancer.
This article was originally published in a special issue, Professional Issues and Trends in Nursing in Japan handled by Editor(s). Dr. Akiko Kondo, Tokyo Women's Medical University, Japan 